\title{
THE LIFE CYCLE OF ERGOT
}

The pharmacognosy of ergot is interesting. Extremely so. And there is still much we do not know. What we do know is not so old. Louis Tulasne in 1853 pointed out ergot's life cycle just a little over a century ago. Shortly afterward some research workers tried artificial infestation on rye. Success was limited. Others tried cultivation on laboratory cultures. Success was limited. It still is. Other investigators studied the relationship of host to species. Success was limited again. Commercial infestation of rye fields has been realized only recently. Culture growth on a commercial scale is still a dream. A dream about to come true. And the complete number of species and hosts is still unknown despite the fact that about 50 of the former and over 600 of the latter already have been listed. Listed. Not studied. Or else only studied meagerly.

Since official ergot comprises only the sclerotium let us see what that means. Sclerotium is from the Greek crx);1Jp6 skleros meaning hard. From the various pharmacopeias we learn that the sclerotia are from I to $5 \mathrm{~cm}$ long and somewhat curved and tapering off at the ends. They have longitudinal furrows and along this plane are obscurely triangled. In color the sclerotia look blackish but are deep purple-brownish. Their short fracture reveals a white, a grey, a pale pink or a slightly lavender color. These small, banana shaped, brittle, blackish ergots are the resting stages of the fungus Claviceps pupurea. The sclerotia. And a good place to begin the life cycle of ergot.

When rye is harvested the sclerotia not otherwise utilized fall to the ground to complete their resting stage. Here they slowly absorb moisture so that by springtime they are ready to begin germination followed by the conidial stage, the ascigerous stage and again the resting or sclerotial stage.

\section{THE PHARMACOGNOSY OF ERGOT}

\section{THE PROBLEM OF COLD}

But let us examine one stage at a time. We left our sclerotium on the cold wintry ground to complete its resting stage. We said it slowly absorbed moisture so that it could germinate in late spring. This is disputed. That is, the absorption of moisture. If only the moisture were necessary then why could not the sclerotia germinate after a heavy rain instead of waiting until spring? No answer. We simply do not know. All we do know is that a dormant period must occur before germination. And that one or more cold periods must chill the sclerotia. Many have studied this problem and each 
investigator has come up with a different answer. Some say that a period of actual frost must take place before germination. Some that germination is helped by previous freezing but is not absolutely necessary. Others dispute these findings. Some investigators claim that actual frost is unnecessary but that cold temperatures are. Heinrich Kirchhoff of Germany in 1929 claimed that a temperature of $2^{\circ}$ to $3^{\circ} \mathrm{C}$ for three to six weeks followed by one to two months at about $15^{\circ} \mathrm{C}$ is the most favorable. Others claim that less than a month is needed for germination if the sclerotia are subjected to cold for two months previously. W. E. Brentzel of Fargo, North Dakota in 1927 froze sclerotia in a refrigerator for 24 hours every two weeks before germination was allowed to take place. About all investigators of this phase do agree upon is that cold of some sort and length is required.

Then again some investigators claim that the sclerotia should be kept covered with damp earth. Some say dry earth or sand. Still others advocate alternate wetting and drying of the sclerotia. Some say sclerotia one year old do not germinate. Others say they do. Claims. Counterclaims. It could be pointed out here that ergot grows in the Canadian prairies, in Finland and in Russia as well as in Spain, Portugal and Algeria. Extremes of weather. And in Switzerland too-just to mention one in-between place. Adding Argentina, Australia and Bengal puts ergot on each continent. The whole question is now academic since controlled artificial infestation of rye can be carried out at will. So we probably shall never know the reason why sclerotia falling to the ground in autumn must wait until late spring to germinate.

\section{GERMINATION OF SCLEROTIA}

The sclerotium is still on the ground. We shall assume that all factors necessary for germination have come into play and germination is taking place. The first thing to be seen is that the little sclerotium has some bumps on it

\section{THE LIFE CYCLE OF ERGOT 17}

generally 6 to 15 but it may have up to 50 or 60 (fig. 2a). These project up like drum sticks and are called stromata (figs. $2 \mathrm{~b}$ and $2 \mathrm{c}$ ).

These stromata are from 15 to $30 \mathrm{~mm}$ long with a rounded head at the free end. The stalk or stipe is usually dark purple while the head, capitulum or spheridium is pinkish. But both may run the gamut from yellow to red to purple (fig. 2d). Inside the head are embedded numerous pear shaped cavities called perithecia (fig. 2e). When the head is mature each perithecium can be located by the papillae surrounding each ostiole-a sort of wart covering the entrance to the pearish cavity (fig. 2f). As further development takes place, from the base or floor of each hollow perithecia arise numerous 
asci or sporangia (fig. 2g). These asci are interspersed with slender hair-like paraphyses (fig. 2h). The asci look like and are long tubes containing threadlike ascospores (fig. 2i). The filamentous ascopores are up to 2,um in diameter and about 60 to 70 ,urn long. As they emerge from the ascus-each of which holds eight and only eight- the ascospores are then dependent upon the wind or splashing rain drops or insects to be dispersed to the growing rye. Some investigators claim that the ascospores are expelled slowly and stick to the sticky substance at the ostioles. Others that they are shot out through the ostioles to distances of up to $8 \mathrm{~cm}$. We do not know. Be that as it may nature has provided that infestation take place because it takes about a week for secondary infection to begin after primary infection with the ascospores. Thus the rye does not need to be in flower when the ascospores are released. Further each stroma twists and bends with the light intensity and therefore neatly points the perithecia in all directions for better dispersion. The direction is always upwards according to the report in 1911 of H. H. Whetzel and Donald Reddick of Cornell University. That is why the twisting and bending of the stromata. Whetzel and Reddick reported that S. J. Rostowzew of Russia noted the same thing in 1902. Each sclerotium produces up to one million ascospores capable of germination. However with new methods of artificial field infestation now developed we are no longer dependent upon the whims of nature to disperse ascospores. But we still need the rye.

\section{HONEYDEW AND CONIDIA}

And now we can go on to the next stage. The conidial stage. Also known as the sphacelia stage. Or honeydew stage. We left our ascospores at the opening of the ascus waiting to be expelled and carried away by air currents or insects. By no matter what the means we now find that one of the ascospores

Fig. 2. From sclerotia to ascospores

Fig. 3. From ascospores-or conidia-to sclerotia

20 THE PHARMACOGNOSY OF ERGOT

Fig. 4. Germinating sclerotia

Fig. 5. Cross sections of stromata enlarged up to $900 \mathrm{x}$. 
Fig. 6. Honeydew on rye.

\section{THE LIFE CYCLE OF ERGOT 23}

spores has landed on a spike of rye such as seen in figure $3 a$ with sclerotia developing. Within 24 hours the ascospore starts to infest the pistil of the flowering rye and the next or conidial stage commences. Damp weather or morning dew causes moisture to accumulate at the base-or ovary-of the pistil and it is there that the ascospore begins to germinate. It produces long filamentous hyphae which enter the ovary. But instead of proceeding the usual normal way of travelling through the stigma and down through the style the hyphae enter the ovary directly from the exterior. They can do this by secreting enzymes which digest the exterior tissues of the pistil. In figures $3 c$ and $3 e$-which are cross sections of figures $3 b$ and $3 d$ respectivelywe see how the ovarian cavity becomes obliterated. Meanwhile the filamentous hyphae get longer and more numerous and by this time are called mycelia and have completely enveloped the pistil except at the stigmaas in figures $3 f$ and its cross section figure $3 \mathrm{~g}$. All this takes from six to eight days. The digested exterior tissues of the pistil-especially the ovary-now have formed a whitish, canal-filled, caseated mass known as the sphacelia. Naturally the ovary has kept on growing during this past week and a sclerotium already has started formation at its lower end. Its upper end now looks more like a sponge because of the twisted strands of hyphae which give rise by abstriction-chocking off-to the oval asexual spores we call conidia. Besides forming the palisades-like conidiophores the hyphae excrete a sweet, yellowish mucilaginous substance-called honeydew-which envelopes the numerous spores or conidia as they are abstricted. Being sweet the honeydew exudate attracts flies, weevils, ants and other insects. Being heavy the honeydew drops fall onto the spikelets of grain below them. Or they may be spread by contact onto adjacent spikes. This of course brings the conidia into contact with other pistils and their ovaries and so spreads the growth of ergot. And brings us into the next and last stage. The ascigerous stage.

\section{COMPLETION OF THE SCLEROTIUM}

We have said that the upper end of the ovary looks rather like a sponge with the lower end already showing a sclerotium forming as shown in figures $3 f$ to $3 \mathrm{i}$. This is due to the more numerous hyphae at the base-from where they started to extend in the first place. As the production of conidia in the upper segments of the ovary tapers off the hyphae filaments at the lower end are still eating through and digesting away the ovarian walls. The 
mass of hyphae or mycelia becomes even more interwoven as the threads

\section{THE PHARMACOGNOSY OF ERGOT}

penetrate ever more deeply and ever more upwards and their branches intersperse themselves among the original filaments. At the same time the hyphae increase in thickness and are divided by transverse walls. By now the hyphae have consumed the whole ovary and penetrated its interior so that there is nothing but hyphae and more hyphae. Mutual pressure of the ever-growing and ever-penetrating threads finally causes a dense mass of compact tissue called the pseudoparenchyma. Meanwhile conidia have ceased to be produced. Honeydew is no longer exudated. And a true cortex is formed on the developing sclerotia. The cortex consists merely of the blackish hyphae on the exterior surface placing themselves parallel to one another. The color is due to deposited pigment. As the sclerotium develops upwardly it eventually replaces the whole grain of rye-as seen in figure $3 f$. When it does it is full grown. Deep purplish brown. Blackish. Hard. Conspicuous among the glumes. Fully grown ergot. A true sclerotium. A sclerotium ready to fall to the ground unless otherwise utilized for making medicines. Its life cycle is now complete. The wheel has come full turn. Thanks to Louis Tulasne of Paris who discovered the whole process in 1853.

\section{MODERN CONCEPTS}

Before Tulasne all was guess work. Some of the various types of ergot sclerotia were known. Some of the plants they grew on were known. But how and why were not. Louis Tulasne showed almost all of the features of how an ergot sclerotia grows. But not all. He did not possess the sophisticated techniques of today. Thus only in 1944 could Arthur Stoll and Artur Brack of Basel report something new. These Swiss research men showed that the ovary of rye per se is not necessary for the development of a sclerotium. That sclerotia on rye can develop at the nodes of rye plants and therefore are not localized to the ovary. Stoll and Brack pointed out that much more was involved than mere relocation of sclerotia. By inoculating the nodes only rarely does a sclerotium develop. But by bending back the ear of rye by snapping or crushing the stalk below it-and in this way throttling the food supply to it-honeydew soon forms and a sclerotium is produced. This brings up the question of whether or not host tissue is involved in the formation of sclerotia.

Egil Ramstad and Gunnar Gjerstad of the United States in 1955 went even further in questioning the concepts of Louis Rene Tulasne. They pointed out that in the developing sclerotium the ovary is found as a deformed 
process at the top of the sclerotium because after infection it becomes

\section{THE LIFE CYCLE OF ERGOT 25}

comes detached from the receptacle. Ramstad and Gjerstad claim that there is no intimate anatomical connection between the fungus and the rye. That the Claviceps purpurea merely growS" directly on the sap from the rye plant which bleeds into the boat-like hollow formed by the paleae of rye flowers. That this plant sap serves as nutrient for the fungus throughout its period of development and that the plant sap exudes into the hollow because the wound after detachment of the ovary fails to heal. Thus honeydew is merely sap of rye and not the ovary transformed into a secretion due to the action of the fungus Claviceps purpurea.

J. Kybal of the Research Institute for Drugs from Natural Sources in Prague in 1964 also reported new observations on the formation of ergot sclerotia. Whereas most investigators studying sclerotial formation employ fixed and stained preparations Kybal made vital preparations by careful dissection and teasing of growing sclerotia. In this manner he could show that germination of the conidia in the honeydew gives rise to sclerotia. And that germination of ergot conidia-under the very same conditions-gives rise to either sphacelial or sclerotial hyphae. But whether this is due to the physiological state of the conidia or to predetermined genetic factors must be investigated. At any rate some germinating conidia form long thin typical sphacelial hyphae but the majority do not. They form thick, two or more celled fibers instead, whose isodiametric cells form typical sclerotial hyphae. In the later stages the long thin sphacelial hyphae regularly intersperse the thicker and longer hyphae growing densely next to and even through each other to form the compact sclerotium. These new investigations by Stoll and Brack, by Ramstad and Gjerstad and by Kybal demonstrate that after almost a dozen decades contributions to the life cycle of ergot can still be made.

\section{REFERENCES}

Brentzel, W.E.: Studies on ergot of grains and grasses. N.D. Agr. Expt. Sta. Bull. 348 (1947).

Kybal, J.: Neue Beobachtungen fiber die Bildung der Sklerotien von Claviceps purpurea (Fr.) Tul. Planta Med. 12: 166-168 (1964).

Ramstad, E. and Gjerstad, G.: The parasitic growth of Claviceps purpurea (Fries) Tulasne on rye and its relation to alkaloid formation. J. amer. pharm. Ass. 44: 741-743 (1955).

Stoll, A. und Brack, A.: Uber die Entstehung von Sklerotien des Mutterkornpilzes (Claviceps purpurea) an den obersten Halmknoten des Roggens. Ber. schweiz. Bot. Ges.

54: 252-254 (1944). 
Tulasne, L.R.: Note sur l'ergot du seigle, Sclerotium clavus DC. C.R. Acad. Sci. 33: 645-647 (1851). - Memoire sur l'ergot des glumacees. Ann. sci. nat. 20: 5-56 (1853). Whetzel, H. H. and Reddick, D.: A method of developing Claviceps. Phytopathology 1: 50--52 (1911). 